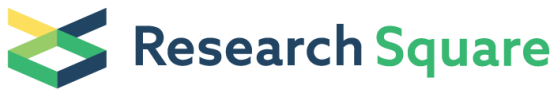 \\ Preprints are preliminary reports that have not undergone peer review. \\ They should not be considered conclusive, used to inform clinical practice, or referenced by the media as validated information.
}

\section{Efficacy and safety of YinQiSanHuang-antiviral decoction on chronic hepatitis B: study protocol for a randomized, placebo- controlled, double-blinded trial}

\section{qing-juan wu}

China Academy of Chinese Medical Sciences Guanganmen Hospital

Wen-Liang Lv ( $\square$ wenlianglv@126.com )

https://orcid.org/0000-0002-4552-919X

Juan-Mei Li

guang'anmen hospital of china academy of Chinese medical sciences.

Ting-Ting Zhang

Guang'anmen Hospital of China Academy of Chinese Medical Sciences.

Wen-hui Zhou

Guang'anmen Hospital of China Academy of Chinese Medical Sciences.

\section{Qiang Zhang}

guang'anmen hospital of china academy of Chinese medical sciences.

\section{Jiu-Chong Wang}

guang'anmen hospital of china academy of Chinese medical sciences.

Qing-Nan Wang

guang'anmen hospital of china academy of Chinese medical sciences.

\section{Ruo-Xuan Zhang}

guang'anmen hospital of china academy of Chinese medical sciences.

\section{Xin Zhao}

guang'anmen hospital of china academy of Chinese medical sciences

\section{Si-Tong Chen}

guang'anmen hospital of china academy of Chinese medical sciences.

\section{Shuang Liu}

guang'anmen hospital of china academy of Chinese medical sciences.

\section{Gao-Hui Li}

guang'anmen hospital of china academy of Chinese medical sciences.

\section{Zheng-Min Cao}

guang'anmen hospital of china academy of Chinese medical sciences.

\section{Lei $\mathbf{X u}$}

guang'anmen hospital of china academy of Chinese medical sciences.

\section{Jing Chen}

guang'anmen hospital of china academy of Chinese medical sciences.

\section{Study protocol}

Keywords: chronic hepatitis B, cirrhosis, traditional Chinese medicine, clinical trial, efficacy

Posted Date: April 15th, 2020

DOI: https://doi.org/10.21203/rs.2.20189/v2

License: (a) (1) This work is licensed under a Creative Commons Attribution 4.0 International License. Read Full License 
Version of Record: A version of this preprint was published at Trials on June 5th, 2020. See the published version at https://doi.org/10.1186/s13063-020-04395-y. 


\section{Abstract}

Introduction: Chronic hepatitis B (CHB) is a global public health problem. Antiviral therapy is the primary treatment. Studies shown that combined therapy of traditional Chinese medicine (TCM) and conventional antiviral drugs has better efficacy than conventional antiviral for treatment of CHB. YinQiSanHuang-antiviral decoction (YQSH) is a TCM compound preparation, and has shown its effect on anti-hepatitis B virus and slowing progression of hepatitis B-related liver diseases. To evaluate the efficacy and safety of YQSH combined with entecavir and its preventive effect on hepatitis B cirrhosis, we designed this randomized, double-blind and placebocontrolled trial, which objective is "the combination of YinQiSanHuang-antiviral decoction with entecavir reduce the annual incidence of liver fibrosis / cirrhosis to $1 \% "$.

Methods: This is a multicenter, randomized, placebo-controlled, double-blinded trial, 5 hospitals involved in. Totally 802 patients are randomly allocated to two groups: the YQSH group $(n=401)$ or the placebo group $(n=401)$. The YQSH group receives YQSH with Entecavir, the placebo group receives granule of placebo with Entecavir. Patients receive treatment for 52 weeks, and then are followed up for $52 \pm 2$ weeks. The primary outcome measure is the annual incidence of cirrhosis. The secondary outcome measures are HBVDNA negative rate, HBsAg negative rate, $\mathrm{HBeAg}$ seroconversion rate, liver function (Alanine aminotransferase (ALT), aspartate aminotransferase (AST), gamma glutamyl transferase (GGT), alkaline phosphatase (ALP), serum albumin (ALB) and total bilirubin (TBIL)), spleen thickness, evaluation scores of patients' clinical symptoms and safety assessment. Outcomes will be assessed at baseline and after treatment.

Discussion: Combination therapy could become a trendy of treatment of $\mathrm{CHB}$, this trial expecting to provide credible clinical evidence for the future combination of TCM and conventional antiviral drugs for the treatment of CHB.

Trial registration: ChiCTR1900021521, this protocol was registered in the Chinese Clinical Trial Registry (URL: http://www.chictr.org.cn) on February $25^{\text {th }}, 2019$.

\section{Background}

Chronic hepatitis B (CHB) is a chronic viral infection caused by Hepatitis B virus (HBV) and characterized by the persistence of $\mathrm{HBs} A \mathrm{~g}$ for at least 6 months (with or without concurrent HBeAg). As a global health problem, more than 257 million people worldwide suffer from chronic HBV infection[1-2]. In 2015, an estimated 887000 deaths resulted from hepatitis B are mostly from cirrhosis and hepatocellular carcinoma (i.e. primary liver cancer), ${ }^{[3]}$ among which CHB is responsible for $30 \%$ of all deaths from cirrhosis and $40 \%$ from hepatocellular carcinoma ( $\mathrm{HCC}) \cdot\left[{ }^{4-6}\right]$ China is one of the highest prevalence country with about 20 million $\mathrm{CHB}$ cases, accounted for $21.5 \%$ among 93 million cases of HBV infection. Without timely testing and treatment, most CHB will develop into cirrhosis, HCC or finally lead to death. $\left.{ }^{7-8}\right] \mathrm{t}$ is estimated that in China there are 20-30 million people with $\mathrm{CHB}, 1$ million with liver cirrhosis and 0.3 million with HCC caused by hepatitis B. ${ }^{[9]}$ Deaths due to HBV-related liver diseases in China (0.308 million deaths per year) account for more than $30 \%$ of the global mortality from $\mathrm{HBV}\left(0.887\right.$ million deaths per year) $\left[{ }^{10]}\right.$. The antiviral therapy is the primary link to slow the conversion of $\mathrm{CHB}$ into cirrhosis, which can effectively restore liver function and improve survival rate in patients with $\mathrm{CHB}$. [1 ${ }^{1-12}$ ] Currently, the US Food and Drug Administration (FDA) has approved two types of anti-hepatitis B virus drugs: interferon (IFN) and nucleos $(\mathrm{t})$ ide analogs (entecavir, lamivudine, telbivudine, adefovir, and tenofovir), although nucleoside analogues are well tolerated and exhibit an early and potent antiviral effect, the selection of resistant mutants and nephrotoxicity during long-term therapy limit their use. [13-14]

Chinese herbal medicine (CHM), as one of the most popular complementary and alternative therapies of CHB, a large number of studies have reported its anti-hepatitis B virus effect. CHMs have two major characteristics: a) it is flexible and variable in various kinds of herbal medicines, it has complex compositions which means not easy causing drug resistance. b) Chinese herbal medicines are taken from the natural environment, with a rich source and easy to obtain. CHMs are generally well tolerated for long-term treatment, which shows good therapeutic effect on the prevention and treatment of CHB. A cohort study showed that the use of $\mathrm{CHM}$ is associated with a significantly reversed cirrhosis and reduced HCC risk in patients with CHB. ${ }^{[5]}$ Lots of researches identified the active ingredients in single herb or in herbal formula has therapeutic effect on $\mathrm{CHB}$, the mechanisms related in anti-HBV, anti-fibrosis, liver protection, anti-tumour, anti-bacterial, antioxidant, anti-acute liver injury and anti-hepatocellular carcinoma. [ ${ }^{16-21]}$ The ideal antihepatitis B virus drugs should have good safety, good drug resistance, long-lasting effects and no withdraw rebound, which can stimulate the host immune responses, and effectively inhibit virus replication or even eliminate the virus. [22-23] Study identified that 
CHM not only has antiviral effect, but also can enhance the body's immunity to improve the antiviral ability. Such as the extract of $L e-$ Cao-Shi, which is a kind of TCM herb, can restrain the expressions of duck hepatitis B model surface antigen (DHBsAg), hepatitis B e antigen (DHBeAg), and HBV-DNA (DHBV-DNA), correspondingly, in a HepG2.2.15 cellular model, it could also significantly inhibit the secretions of $\mathrm{HBsAg}$ and $\mathrm{HBeAg} .{ }^{[24]}$ And another study results demonstrate that cordycepin, which extracted from traditional Chinese medicine, could work as adjuvant to hepatitis $b$ vaccine and this kind of new vaccine simultaneously improves the humoral and cellular immunity of BALB/c mice without side effects. ${ }^{[25]}$ YinQiSanHuang-antiviral decoction (YQSH) is a CHM formula used over thirty years for CHB treatment, which has showed effects on anti-HBV-DNA and increasing the level of alanine aminotransferase (ALT) in a small-scale clinical study. ${ }^{26]}$ Research results suggested that YQSH not only enhances the antiviral effect of entecavir, but also has a significant prevention effect on $\mathrm{CHB}$ related cirrhosis. So, we designed this study and setting the objective as "the combination of YQSH with entecavir reduce the annual incidence of liver fibrosis / cirrhosis to $1 \%$ " to test the effectiveness of this combination.

\section{Methods}

\section{Study setting}

A total 802 patients will be recruited from 5 centers: the main responsible unit XiXi Hospital of HangZhou will recruit 162 cases, BeiJing ShunYi Traditional Chinese Medicine Hospital will recruit 160 cases, the Sixth People's Hospital of ShenYang will recruit 160 cases, BeiJing DiTan Hospital Capital Medical University will recruit 160 cases, ChengDu University of Chinese Medicine Affiliated Hospital recruit 160 will cases.

\section{Eligibility criteria:}

\section{Inclusion criteria}

The inclusion criteria are as follows: a) patients have a history of hepatitis B infection or HBsAg positive for more than six months, and the current HBsAg and/or HBV-DNA are still positive. b) patients who cater for antiviral indications in the 'Asian-Pacific consensus statement on the management of chronic hepatitis B: a 2008 update' [27], or patients taking Entecavir dispersible tablets are also can be included in. (this study will enroll patients those who had taken entecavir previously, conversely, patients who had taken immune stimulatory drug or other antiviral drugs within 3 months will not enrolled.) c) between 18 to 65 years old. d) patients show syndromes of liver stagnation and spleen deficiency and dampness in TCM. For the TCM diagnostic criteria, we refer to 'National Standards for TCM Clinical Diagnosis and Treatment of the People's Republic of China'[28]and the 'Medical Consensus of diagnosis and treatment of cirrhosis with integrated TCM and Western medicine',[29] which was published by Digestive System Diseases Committee, Society of Integrated Traditional Chinese and Western Medicine.

\section{Exclusion criteria}

The exclusion criteria are as follows: a) patients with cirrhosis. b) patients with liver cancer. c) patients in acute and chronic hepatitis with non-HBV infection, autoimmune hepatitis, primary biliary cirrhosis, primary sclerosis cholangitis, inherited metabolic liver disease, drug or toxic hepatitis, alcoholic liver disease. d) pregnant or lactating women or women planning to become pregnant during the study period, e) patients who are allergic to the test drugs. f) patients who have mental disorders that cannot cooperate with the study, or patients with epilepsy in unstable status. g) patients with severe systemic diseases related with heart, brain, lung, kidney, and hematopoiesis. h) patients of alcoholism or with other unsuitable conditions that not suitable for enrollment. For those patients who are already using TCM, we will not enroll them unless they have stop using TCM for more than three months.

\section{Interventions:}

\section{Description}

All patients will do the screening test during the screening period in clinic, whether they meet the inclusion criteria. The screening evaluation includes: the general situation, disease-related symptoms and signs, and corresponding laboratory tests, including: urine pregnancy test (women of childbearing age), HBV DNA, liver function, FibroScan, Liver B-ultrasound or MRI/CT and other examinations. The test group (YQSH group) receives YQSH formula granules $5 \mathrm{~g}$ (brewed with $150-200 \mathrm{ml}$ water before taken $\searrow$ twice a day, combined with Entecavir $0.5 \mathrm{mg}$ once a day. The control group (placebo group) receives YQSH placebo formula granules $5 \mathrm{~g}$ (brewed with 150-200ml water before taken囚twice a day, combined with Entecavir $0.5 \mathrm{mg}$ once a day. The Entecavir was produced by 
ChiaTai TianQing Pharmaceuticals in Jiangsu, China (production batch number: H20100019). The main compositions of YQSH, totally 14 kinds of herb, are shown in Table 1. The test drugs are made into Chinese medicine formula granule. Before taking YQSH, boil the mixed formula granule with 150-200 ml water for 3-5 minutes. YQSH placebo is made of excipients, thinners, coloring agents, flavoring agents and fried malt, which is similar to YQSH in the shape, color, smell and taste.

\section{Modifications}

If the patient shows abnormal liver function (such as ALT>2*ULN) during the trial, it should prompt temporary or permanent cessation of treatment, and the investigator could add hepatoprotective drugs such as Silibinin and other drugs according to the patient's condition. At the same time, the researchers will record and follow up the situation of these patients closely. If the patient's ALT returns to normal after liver protection treatment, and with a normal direct bilirubin and INR at the same time, then they may have a chance to continue the trial; otherwise, these patients will stop the trial permanently for the safety reasons. If the following conditions occur, the subjects should discontinue the trial: a) poor compliance, irregular taking medicine, failure to revisit or revisit on time. b) some combined diseases or complications, or deterioration during the trial. c) subject self-withdrawal. d) combined other drugs, or not taking test drugs according to research regulations. e) lost contact. f) cannot provide complete information.

There are specific stopping criteria: a) serious safety problems occurred during the test, and the test should be stopped in a timely manner. b) the drug was found to have no clinical value during the trial, and the trial should be stopped to avoid delaying the effective treatment of subjects. $\mathrm{c}$ ) it is found in the trial that there is a major error in the clinical trial protocol and it is difficult to evaluate the effect of the drug; or a well-designed protocol with important deviations in the implementation, and it is difficult to continue to evaluate the efficacy and safety of the drug. d) the sponsor requested stopping (such as funding reasons, management reasons, etc.). e) the State Food and Drug Administration of China ordered the trial to be stopped for some reason. $\mathrm{f}$ ) the test is suspended due to force majeure reasons.

\section{Adherence}

The study will be regularly monitored by a Clinical Research Associate (CRA) in accordance with the corresponding standard operating procedure. The CRA will help ensure that the research center adheres to the research protocol, arranges the supply of research drugs, and ensures that the drugs are kept under appropriate conditions in accordance with instructions. At the beginning of the trial, the researcher would emphasize the importance of compliance to the subjects, and require the subjects to bring back drug package (regardless of the remaining drugs) when they visited the research center. At the same time, we will establish online platform to make immediate contact with the patient, and contact the patients at least twice a month to learn the patient's situation and remind patients to actively return to the clinic. And for those patients who were effective during the treatment but could not complete the entire course, and those lost to follow-up, these data will be included in the efficacy statistics and should be analyzed intentionally.

\section{Concomitant care}

Other antiviral medicines must not be taken during the trial, such as tenofovir or lamivudine, if the un-antiviral medicines combined, record them in the 'Case Report Form (CRF). If the subjects need other treatment or concomitant care, they should contact the doctor in advance.

\section{Outcomes:}

\section{Primary outcome}

The primary outcome is the annual incidence of cirrhosis (the examination methods include liver instantaneous elastic hardness test, abdominal B-ultrasound test or abdominal MRI/CT imaging).

The primary outcome is evaluated before the treatment, at the 52 weeks of treatment, and the $52 \pm 2$ weeks of follow-up.

\section{Secondary outcomes}

The secondary outcomes include HBV-DNA negative rate, HBsAg negative rate, HBeAg seroconversion rate, liver function (ALT, AST, GGT, ALP, ALB and TBIL), spleen thickness, and the evaluation scores of patients' clinical symptoms. 
These indicators are observed before the treatment, at the 26 weeks of treatment, the 52 weeks of treatment, the $26 \pm 2$ weeks of followup period, and the $52 \pm 2$ weeks of follow-up period.

\section{Safety outcomes}

The safety outcomes include the adverse events (AE), laboratory test (liver function, kidney function, blood routine test, urine routine test, et al), electrocardiogram (ECG), basic vital signs, and physical examination.

And the basic vital signs are body temperature, blood pressure, respiration and heart rate; laboratory tests include renal function tests, blood urea nitrogen (BUN), creatinine ( $\mathrm{Cr}$ ), blood, stool and urine routine tests. These biological indicators are monitored from the grouping of these patients until the end of follow-up. (Figure 2)

\section{Participant timeline}

The treatment period is 52 weeks and the follow-up assessment period will last for $52 \pm 2$ weeks. We draw two figures to make the participant timeline more clearly.

(Figure 1\& Figure 2)

\section{Sample size}

The aim of this study is to reduce the annual incidence of cirrhosis from $2 \% \sim 10 \%\left[{ }^{[30]}\right.$ to $1 \%$ in CHB patients. Therefore, according to the sample size estimation formula for comparison of two sample rates, the incidence of target events is less than 0.2 (or 0.3 ) or greater than 0.8 (or 0.7 ), estimation formula as follows:

$$
\mathrm{n}=\frac{\left(u_{\alpha}+u_{\beta}\right)^{2}}{2\left(\sin ^{-1} \sqrt{p_{e}}-\sin ^{-1} \sqrt{p_{c}}\right)^{2}}
$$

The and represent the incidence rates of test group (YQSH group) and placebo group (control group) respectively, the positive event rate 0 in the control group is $5 \%$, while the target event rate () in the test group is set to $1 \%$. Since the values of and are small, so the degree is measured in radians, $a=0.05, \beta=0.10$. In this study, two-sided test was chosen, $=1.96,=1.282,=0.05,=0.01$. The calculated sample size of each group is approximately 334 cases, allowing for $20 \%$ attrition, therefore, the total number of patients required for this trial is $334 *(1+20 \%) * 2=802$ cases, with 401 in each group.

\section{Recruitment}

Outpatients in clinics are the main recruitment objects. Posters and online publicity with a brief introduction to the trial and the contact information of researchers will also be used for recruitment. Before enrollment, each patient is provided with a complete and comprehensive description of the test procedure, purpose, potential adverse events and expected benefits. Subjects are also informed that they may withdraw from the trial. If the patient agrees to participate in the trial, the subject will sign two informed consent forms, one kept by the patients and the other one kept by the researcher. For subjects with involuntary or incomplete autonomy, these patients can also enter the trial after the consent of the ethics committee, and the informed consent will be signed by of their guardian.

\section{Allocation}

\section{Sequence generation and implementation}

Central Randomization System (CRS) is applied for a completely randomized design. The randomized system mainly includes the following modules: subject screening, randomization, emergency blinding, drug formulation, drug supply management, and other functional modules. Central random principle: The researcher uses the screening module to enter some basic information of the subject (such as date of birth, gender) and obtain the subject's unique identification number (SIN). Firstly, confirm patients with the inclusion criteria, log into the CRS, input the general information of the subjects, generate the random number and fill in the eCRF. 
Secondly, drug distributors apply for the drug number from CRS according to the random number. Finally, the drug senders verify the code on the drug package with the number in the system, then the drugs been given to patients.

\section{Concealment mechanism}

In this study, the central randomization system was used to centrally control the allocation of entire randomization scheme. The "central randomization" method was used to conceal the allocation: when researchers determined that the subjects were qualified, the researchers log in to the central random system, enter some basic information of the subject and obtain the subject's SIN. Then, the central random system will assign subject random number and drug number according the designed blind table. In order to make the blind method effective and reduce drug loss, the random numbers are separated from the drug numbers in this system. Although the random number and the drug number are different, their corresponding treatment plans are consistent within the system.

\section{Blinding and emergency unblinding}

This is a double-blind trial. The blinding method is set up and implemented by the Medical Statistics Center of Tianjin University of TCM. Neither the study researchers nor the subjects know the medication grouping. In the course of the trial, there is a scientific and strict management implementation system and feasible operation methods. All the subjects are under a standardized observation with their clinical symptoms carefully recorded. Adverse reactions are carefully observed, and 'emergency unblinding' is required for serious adverse reactions.

A regular supervision, inspection and return system to ensure the implementation of double-blinding method.

Unblinding at the end of the test to perform a statistical analysis of all the data. The outcome assessment will be blinded. After all the research data has been entered and locked, the third party participants who save the blinding codes and the researchers will jointly unblind and submit the database to the statistical analyst. When all the statistical analysis is completed, reports of statistical analysis and clinical trial summary are gonna been written by researchers.

\section{Data collection plan and data management}

The investigator will prepare original documents for each subject who randomly entered the study, information will be recorded in the CRF. All research results (including personal data, test documents, etc.) that appear in the original medical records will be completely confidential within the scope allowed by law. Subjects name will not appear in the CRF, only the name initials and the random number will be shown. The content should be comprehensive and accurate, so as to record all examination results and other relevant data. The research center shall keep these documents properly for 5 years after the end of the research. The researcher will authorize the relevant regulatory agency to directly access all research-related documents.

There are principles for handling the follow up losing: a) if the loss is because of adverse reactions, the data will be record in the adverse reaction statistics; b) if the loss is because of ineffectiveness, the data will be included in the efficacy statistics; c)for those patients who were effective during the treatment but could not complete the entire course, and those lost to follow-up, these data will be included in the efficacy statistics and should be analyzed intentionally.

\section{Statistics:}

\section{Outcomes}

For the statistical analysis of the comparison of the primary outcome incidence between the two groups, we will use the $\chi 2$ test and setting $\mathrm{P}<0.05$ ( $95 \%$ confidence interval) as statistically significant; and for the secondary outcomes: where the measurement data is expressed as mean \pm standard deviation, the count data is expressed as frequency and percentage (f,\%), and the frequency or percentage of the efficacy evaluation index is converted into frequency and percentage $(\mathrm{f}, \%)$. For the comparison of the mean between the two groups, the homogeneity test is performed first. If the variances are equal, the $t$ test is used. If not discarded, the nonparametric $t$ 'test is used. The measurement data of each group before and after treatment is compared using the paired $t / t$ ' test. The comparison of grid table count data was performed using the $\chi 2$ test, and the comparison of rank data used the rank sum test. $P<0.05$ was used as the statistical difference. The data analysis will be performed by SPSS 19.0 statistical software. 
The baseline is defined as the last observation data before the first medication $₫$ which included demographic characteristics and clinical baseline datas $\ a g e$, sex, vital signs (height, weight, temperature, heart rate, blood pressure, breathing), clinical symptom score, HBV-DNA, Liver stiffness(FibroScan/Fibrotouch), Entecavir treatment history, CHB related diseases.

\section{Additional analyses}

We haven't plan to do subgroup analyses or sensitivity analyses currently.

\section{Analysis population and missing data}

We will use three methods to do statistical analysis data:

Full Analysis Set (FAS): According to the Intentional Therapy (ITT) principle, all randomized subjects' data will enter the full analysis set. For subjects who withdraw from the study early for various reasons, the missing data will be filled by the way of last observation carry forward (LOCF).

Per-protocol Set (PPS): For those who enter the study and complete treatment and follow-up, the medication compliance is $80-120 \%$, no combined medication that affected the effectiveness evaluation during the study period, with complete evaluation index data and no major test protocol violations, their indictor data will constitute the study's Per-protocol Set.

Safety set (SS): includes those subjects who received at least once treatment after randomization.

\section{Monitoring}

\section{Formal committee and confidentiality}

Composition of data monitoring committee (DMC) will monitor the trial in accordance with the corresponding standard operating procedure, which is independent from the sponsor. The DMC will be allowed to evaluate the quality and integrity of the study. Before the start of clinical trials, uniform training should be conducted for all the participators in clinical trials, which including Good Clinical Practice (GCP), research protocols, Electronic Data Capture System, central stochastic systems, and the use of scales. The DMC will assess the capabilities of research centers and collect information about institutional facilities and technical equipment. During the period of study, the DMC is responsible for verifying the clinical research records with the original records, and resolving any problems that arise during the trial. The DMC will monitor whether written consent and dated informed consent forms (ICF) have been obtained from all subjects. The DMC will also monitor that the research center adheres to the research protocol, arranges the supply of research drugs, and ensures that the drugs are kept under appropriate conditions in accordance with instructions. Each center should submit the main indicators to the clinical endpoint committee to be evaluated by uniform standard. The principal investigator and authorized researcher should review, electronically sign and date the eCRF.

\section{Interim analysis}

DCM have access to interim results and make the final decision with the sponsor an researcher to terminate the trial.

\section{Harms}

Any adverse medical events that occur during treatment and follow-up, regardless of whether or not there is a causal relationship with the test medicines, should be considered as an adverse event (AE) and recorded in the specified case report form(CRF) adverse event table. When filling out the AE report forms, it is necessary to detailed record the occurrence, time, severity, duration, measures taken and outcomes of adverse events. If serious adverse events occur during the trial, emergency treatments should be taken immediately and report to the lead researcher of the trial, the ethics committees and the China State Food and Drug Administration Safety Supervision Department within 24 hours. All the adverse events should be tracked until the adverse symptoms disappear or the researchers confirm that further follow-up is no longer needed.

If the subject has an injury that is directly related to this study during the course of treatment, and it is confirmed by the medical identification, the research team will pay the subject medical expenses; For serious adverse events caused by drug-related injuries, the research team will give the subject certain compensation in accordance with relevant national laws and regulations, and the compensation costs will be borne by Guang'anmen Hospital. 


\section{Auditing}

Beginning with enrollment, each research center will receive auditing visits every three months. After the data is recorded, a professional medical review would be conducted to compare the data entered in the case report form (CRF) with the original data, which is to ensure the quality of the data, the clinical logic, and general medical terms for the description. The researcher will properly keep the data to protect the rights and privacy of subjects, the documents in the clinical trial shall be preserved and managed in accordance with the requirements of the GCP, and the database will be maintained by Electronic Data Capture System (EDC). The auditing procedures if independent from the investigators.

\section{Discussion}

Hepatitis B is a hidden killer. In the course of viral infection for decades, the virus carrier (patients) may show only mild symptoms, which difficult to detected, but it may develop into liver cancer ultimately.[11] Currently, the direct-acting antiviral agents (DAAs) includes NAs and IFN can only control hepatitis B virus, but cannot eliminate it completely. Therefore, pre-treatment is the best way to prevent the deterioration of $\mathrm{CHB}$ and cirrhosis. In the theory of traditional Chinese medicine, there is a viewpoint 'preventive treatment of disease', which means precaution should be paid in advance when the disease has no occurred or already occurred, in case of diseases further development or deterioration. In China, $\mathrm{CHM}$ has been used over two thousand years and played an important role in the prevention and treatment of diseases. TCM decoction is generally composed by various of Chinese herbs with a certain proportion, its characterized by a multi-targets effect. YQSH is a TCM decoction based on the theory of 'preventive treatment of disease' of TCM, in the early small-scale clinical observation, it has suggested a potential effect on delaying the development of CHB related cirrhosis.

At present, long-term HBV-DNA inhibition or HBsAg negative is considered to be the best surrogate endpoint for antiviral therapy in patients with $\mathrm{CHB}$ or cirrhosis associated with HBV. $\left[3^{2-35]}\right.$ Studies reported that combined therapy is superior to conventional antiviral therapies, $\left[3^{6-38]}\right.$ which not only can enhance the antiviral ability, on the other hand, it also can reduce the accompanying symptoms, improve the quality of life and prolong the life of patients. $\left[3^{9-40]}\right.$ Thus, the combination therapy could become a trendy of $\mathrm{CHB}$ treatment. Looking back on the clinical researches about the combination therapy in CHB in recent years, there are mostly single-center, single-field and small sample study, which makes it conclusion less credible. Therefore, this trial protocol was designed into a multicenter, randomized, double-blind, placebo-controlled clinical trial, follow-up as long as $52 \pm 2$ weeks, to verify the clinical efficacy and safety of the combination therapy of YQSH + entecavir, expecting to provide credible clinical evidence for the future combination of TCM and Western medicines for the treatment of CHB.

There are also some limitations to the study that should be considered. Due to restrictions in research project funds and trial period, the follow-up period couldn't be longer, and thus additional randomised controlled trials with long-term follow-up are warranted. For the combination therapy, there are still some problems should be clarified, such as how the drugs are combined, what's the best time for combination therapy, when to stop the drug, whether it can be repeated after stopping the drug, and how to cope with recurrence after drug withdrawal. It is supposed that more combination therapy will be explored in the future based on different mechanisms.

\section{Trial Status}

The protocol version number is 1 and was finalized in October 2018. The date recruitment began on 21 October 2019. The approximate date when recruitment will be completed is December 2021. If it should amend the protocol, we will communicate with the investigators Ethics Committee, trial registries and other relevant parties.

\section{List Of Abbreviations}

CHB, chronic hepatitis B; YQSH, YinQiSanHuang-antiviral decoction; ALT, alanine aminotransferase; AST, aspartate aminotransferase; GGT, gamma glutamyl transferase; ALP, alkaline phosphatase; ALB, serum albumin; TBIL, total bilirubin; TCM, traditional Chinese medicine; YQSH, YinQiSanHuang-antiviral decoction; ECG, electrocardiogram; HBV, Hepatitis B virus; DAAs, antiviral agents; $A E$, adverse event; GCP, Good Clinical Practice; BUN, blood urea nitrogen; FDA, Food and Drug Administration; IFN, interferon; NAs, Nucleos(t)ide aAnalogues; CHM, Chinese Herbal Medicine; CRS, Central Randomization System; CRF, Case Report Form; CRS, Central Randomization System; HCC, Hepatocellular Carcinoma. 


\section{Declarations}

Ethics approval and consent to participate $\bigotimes$ The protocol has been approved by the Medical Ethics Committee of Hangzhou Xixi Hospital, China (which is the central ethical approva), and the other centres in the trial will not begin recruiting until local ethical approval has been obtained. All study participants will sign two informed consent forms, one kept by the patients and the other one kept by the researcher. The results of this study will be published in a peer reviewed journal.

Consent for publication $₫$ According to the terms of the informed consent, unless the subject's consent is obtained, all the subject's personal information is confidential and will not be disclosed to the public. When it is necessary, the drug supervision and administration department, ethics committee, or project funding department may consult the data of the subjects. If without permission, they will not use the subject's information for other purposes or disclose it to other groups.

Data access and dissemination policy: This is an Open Access article which permits others to distribute, remix, adapt, build upon this work non-commercially, and license their derivative works on different terms, provided the original work is properly cited and the use is non-commercial. Trial final results will be disseminated via publication.

Competing interestsロAll authors confirm that this article content has no conflict of interest.

Funding $\square$ This project is sponsored by the National Key R\&D Program of China (No. 2018YFC1705700).

Roles and contributions $\square \mathrm{L}-\mathrm{WL}$ conceptualized the idea and revised it critically for intellectual content, provided professional advices. WQJ wrote the first draft of this manuscript. All authors read and approved the final manuscript. L-JM, Z-TT, Z-Q, W-JC, W-QN, Z-RX and C-ZM were involved in the conception and design, statistical advice and final approval of the manuscript, we will have ultimate authority over these activities.

AcknowledgementsロWe would like to thank professor Zhou Bing for polishing manuscript.

\section{References}

[[1]] Revill PA, Penicaud C, Brechot Christian, et al. Meeting the Challenge of Eliminating Chronic Hepatitis B Infection. Genes (Basel). 2019;10:undefined.

[2] Schweitzer A, Horn J, Mikolajczyk R T, et al. Estimations of worldwide prevalence of chronic hepatitis B virus infection: a systematic review of data published between 1965 and 2013. Lancet. 2015;386:1546-1555.

[3] Liu J, Liang WN, Jing WZ, et al. Countdown to 2030: eliminating hepatitis B disease, China. Bull, World Health Organ. 2019;97:230238.

[4] Vittal A, Ghany M G. WHO Guidelines for Prevention, Care and Treatment of Individuals Infected with HBV: A US Perspective. Clin Liver Dis. 2019;23:417-432.

[5] Stanaway J D, Flaxman A D, Naghavi M, et al. The global burden of viral hepatitis from 1990 to 2013: findings from the Global Burden of Disease Study 2013. Lancet. 2016;388:1081-1088.

[6] Dandri M, Locarnini S. New insight in the pathobiology of hepatitis B virus infection. Gut. 2012;2:16-17.

[7] World Health Statistics 2018: Monitoring health for the SDGs. WHO. 2018;6 June.

[8] Bhattacharya D, Thio C L, Reviewof. Hepatitis B therapeutics. Clin Infect Dis. 2010;51:1201-1208.

[9] Shan S, Jia J. Advances and challenge in prevention and treatment of hepatitis B in China. Zhongguo Bingdubing Zazhi. 2017;01:5-8.

[[1]0] Subic M, Zoulim F. How to improve access to therapy in hepatitis B patients. Liver Int. 2018;38 Suppl 1:115-121.

[11]Yuen Man F, Gane Edward J, Kim Dong J, et al. Antiviral Activity, Safety, and Pharmacokinetics of Capsid Assembly Modulator NVR 3-778 in Patients with Chronic HBV Infection. Gastroenterology. 2019;156:1392-1403.

Page $10 / 15$ 
[[1]2]Calvaruso V, Craxì A. Regression of fibrosis after HBV antiviral therapy. Is cirrhosis reversible? Liver Int. 2014;85-90.

[[1]3]Sun D J, Zhu L J, Yao D H, et al. Recent progress in potential anti-hepatitis B virus agents: Structural and pharmacological perspectives. Eur J Med Chem. 2018;147:205-217.

[[1]4]Lee S H, Cheon G J, Kim H S, et al. Tenofovir disoproxil fumarate monotherapy is superior to entecavir-adefovir combination therapy in patients with suboptimal response to lamivudine-adefovir therapy for nucleoside-resistant HBV: a 96-week prospective multicenter trial. Antiviral Therapy. 2018;23:219-227.

[[1]5]Tsai T Y, Livneh $\mathrm{H}$, Hung T H, et al. Associations between prescribed Chinese herbal medicine and risk of hepatocellular carcinoma in patients with chronic hepatitis B: a nationwide population-based cohort study. BMJ Open. 2017;7:e014571.

[[1]6]Zhao Y , Geng C A, Ma Y B, et al. UFLC/MS-IT-TOF guided isolation of anti-HBV active chlorogenic acid analogues from Artemisia capillaris as a traditional Chinese herb for the treatment of hepatitis. J Ethnopharmacol. 2014;156:147-154.

[[1]7]Han J M, Kim H G, Choi M K, et al. Artemisia capillaris extract protects against bile duct ligation-induced liver fibrosis in rats. Exp Toxicol Pathol. 2013;65:837-844.

[[1]8]Zhao T T, Tang H L, Xie L, et al. Scutellaria baicalensis Georgi. (Lamiaceae): a review of its traditional uses, botany, phytochemistry, pharmacology and toxicology. J Pharm Pharmacol. 2019;71:1353-1369.

[[1]9]Park H S, Park K I, Hong G E, et al. Korean Scutellaria baicalensis Georgi methanol extracts inhibits metastasis via the Forkhead Box M1 activity in hepatocellular carcinoma cells. J Ethnopharmacol. 2014;155:847-851.

[20]Hsu Y L, Kuo P L, Tzeng T F, et al. Huang-lian-jie-du-tang, a traditional Chinese medicine prescription, induces cell-cycle arrest and apoptosis in human liver cancer cells in vitro and in vivo. J Gastroenterol Hepatol. 2008;23:e290-299.

[2[1]]Ohta Y, Sasaki E, Nishida K, et al. Preventive effect of oren-gedoku-to (huanglian-jie-du-tang) extract on progression of carbon tetrachloride-induced acute liver injury in rats. Am J Chin Med. 1997;25:57-68.

[22]European Association for the Study of the Liver. EASL 2017 Clinical Practice Guidelines on the management of hepatitis B virus infection. Hepatol. 2017;67:370-398.

[23]Terrault N A, Bzowej N H, Chang K M, et al. AASLD guidelines for treatment of chronic hepatitis B. Hepatology. 2016;63:261-283.

[24]Zhao Q, Ren X, Chen M, et al. Effects of traditional Chinese medicine formula Le-Cao-Shi on hepatitis B: In vivo and in vitro studies. J Ethnopharmacol, 2019;244:112132.

[25]Wang J B, Liu R, Liu B X, et al. Systems Pharmacology-based strategy to screen new adjuvant for hepatitis B vaccine from Traditional Chinese Medicine Ophiocordyceps sinensis. Sci Rep. 2017;7:44788.

[26]Wang D P. Clinical study of Yinzhi Sanhuang Jiedu Decoction combined with entecavir in the treatment of chronic hepatitis B. Beijing University of Chinese Medicine. 2018;63-64.

[27]Liaw Y F, Leung N, Kao J H, et al. Asian-Pacific consensus statement on the management of chronic hepatitis B: a 2008 update. Hepatol Int. 2008;2:263-283.

[28]State Bureau of Technical Supervision. National Standards for TCM Clinical Diagnosis and Treatment in the People's Republic of China: Symptoms Section. Beijing: China Standard Press. 1997;4:55.

[29]Chinese Society of Integrated Traditional and Western Medicine, Digestive System Diseases Committee. Consensus on diagnosis and treatment of cirrhosis with integrated traditional Chinese and Western medicine. Chinese Journal of Integrated Traditional and Western Medicine on Digestion. 2011;19:277-279.

[30]Fattovich G, Bortolotti F, Donato F. Natural history of chronic hepatitis B:special emphasis on disease progression and prognostic factors[J].J Hepatol,2008,48(2):335-352. 
[31]Tu T, Sandra B, Bartenschlager R. Chronic viral hepatitis and its association with liver cancer. Biological Chemistry. 2017;398:817837.

[32] Terrault N A, Bzowej N H,Chang K M, et al. AASLD guidelines for treatment of chronic hepatitis B. Hepatology. 2016;63:261-283.

[33] Liaw Y F, Kao J H, Piratvisuth T, et al. Asian-Pacific consensus statement on the management of chronic hepatitis B: a 2012 update. Hepatology International. 2012;6:531-561.

[34]Testoni B, Levrero M, Zoulim F. Challenges to a Cure for HBV Infection. Seminars in Liver Disease. 2017;37:231-242.

[35]Lok Anna S, Zoulim Fabien, Dusheiko Geoffrey, et al. Hepatitis B cure: From discovery to regulatory approval. J Hepatol. 2017;67:847-861.

[36] He M, Wu Y, Wang M M, et al. Meta-analysis of the clinical value of oxymatrine on sustained virological response in chronic hepatitis B. Ann Hepatol. 2016;15:482-491.

[37]Zhang L, Schuppan D. Traditional Chinese Medicine (TCM) for fibrotic liver disease: Hope and hype. Journal of Hepatology. 2014;61:166-168.

[38]Kang H, Zhao Y, Li C, et al. Integrating clinical indexes into four-diagnostic information contributes to the Traditional Chinese Medicine (TCM) syndrome diagnosis of chronic hepatitis B. Sci Rep. 2015;5:9395.

[39]Chen J X, Xu Q X, Wang J H, et al. A Case of Recurrent Hepatocellular Carcinoma Acquiring Complete Remission of Target Lesion With Treatment With Traditional Chinese Medicine. Integr Cancer Ther. 2017;16:597-604.

[40]Xiong X, Yang X, Liu Y, et al. Chinese herbal formulas for treating hypertension in traditional Chinese medicine: perspective of modern science. Hypertension Research Official Journal of the Japanese Society of Hypertension. 2013;36:570-579.

\section{Table 1}


Table 1 Main components of YinQiSanHuang-antiviral decoction

\begin{tabular}{|c|c|c|c|c|c|c|c|}
\hline \multicolumn{8}{|c|}{ Table 1 Main components of YinQiSanHuang-antiviral decoction } \\
\hline $\begin{array}{l}\text { Chinese } \\
\text { name }\end{array}$ & Latin name & English name & $\begin{array}{c}\text { pharmacological } \\
\text { action }\end{array}$ & Main active ingredient & $\begin{array}{l}\text { The original } \\
\text { producing } \\
\text { area }\end{array}$ & $\begin{array}{l}\text { Medicinal } \\
\text { part }\end{array}$ & Dosage/(g) \\
\hline $\begin{array}{c}\text { Huang } \\
Q i\end{array}$ & $\begin{array}{l}\text { Astragalus } \\
\text { propinquus } \\
\text { Schischkin }\end{array}$ & Radix Astragali & $\begin{array}{l}\text { Promote liver cell } \\
\text { growth, anti-liver } \\
\text { fibrosis, antiviral, } \\
\text { regulate immunity }\end{array}$ & $\begin{array}{l}\text { Astragaloside }(\square, 0, \square), \\
\text { Calycosin }\end{array}$ & $\begin{array}{l}\text { Neimenggu, } \\
\text { China }\end{array}$ & Rhizome & 12 \\
\hline $\begin{array}{c}\text { Yin } \\
\text { Chen }\end{array}$ & $\begin{array}{c}\text { Artemisia capillaris } \\
\text { Thunb. }\end{array}$ & $\begin{array}{c}\text { Virgate } \\
\text { Wormwood } \\
\text { Herb Capillary } \\
\text { Wormwood } \\
\text { Herb }\end{array}$ & $\begin{array}{l}\text { Lower blood lipids to } \\
\text { treat fatty } \\
\text { liver, reduce alcoholic } \\
\text { liver damage, inhibit } \\
\text { the replication of } \\
\text { hepatitis B virus DNA }\end{array}$ & $\begin{array}{c}\text { Capillin, capillene, } \\
\text { capillanol, capillarisin, 6ロ7- } \\
\text { dimethylsculetin }\end{array}$ & $\begin{array}{c}\text { Shanxi, } \\
\text { China }\end{array}$ & $\begin{array}{l}\text { Aboveground } \\
\text { part of the } \\
\text { plant }\end{array}$ & 12 \\
\hline $\begin{array}{l}\text { Huang } \\
\text { Qin }\end{array}$ & $\begin{array}{c}\text { Scutellaria } \\
\text { baicalensis Georgi }\end{array}$ & $\begin{array}{c}\text { Baical Skullcap } \\
\text { Root }\end{array}$ & $\begin{array}{c}\text { Anti-hepatocyte } \\
\text { inflammation, anti- } \\
\text { hepatocyte } \\
\text { apoptosis, anti- } \\
\text { hepatocyte } \\
\text { mitochondrial lipid } \\
\text { peroxidation, regulate } \\
\text { immunity }\end{array}$ & $\begin{array}{c}\text { Baicalein, neobaicalein, } \\
\text { skullcapflavoneø, baicalin, } \\
\text { wogonin }\end{array}$ & $\begin{array}{l}\text { Hebei, } \\
\text { China }\end{array}$ & Rhizome & 3 \\
\hline $\begin{array}{l}\text { Huang } \\
\text { Lian }\end{array}$ & $\begin{array}{l}\text { Coptis chinensis } \\
\text { Franch. }\end{array}$ & Coptis Root & $\begin{array}{c}\text { Anti-hepatocyte } \\
\text { mitochondrial lipid } \\
\text { peroxidation, inhibit } \\
\text { hepatoma cell } \\
\text { proliferation, prevent } \\
\text { liver fibrosis } \\
\end{array}$ & $\begin{array}{l}\text { Berberine, coptisine, } \\
\text { epiberberine, } \\
\text { berberrubine, palmatine }\end{array}$ & $\begin{array}{l}\text { Sichuan, } \\
\text { China }\end{array}$ & Tuber root & 3 \\
\hline $\begin{array}{c}\text { Huang } \\
\text { Bai }\end{array}$ & $\begin{array}{c}\text { Platycladus } \\
\text { orientalis (Linn.) } \\
\text { Franco }\end{array}$ & $\begin{array}{l}\text { Bark of Chinese } \\
\text { Corktree }\end{array}$ & $\begin{array}{c}\text { Inhibit immune } \\
\text { response, Selective } \\
\text { inhibit HBAg, anti- } \\
\text { inflammatory }\end{array}$ & $\begin{array}{c}\text { Berberine, phellodendrine, } \\
\text { magnoflorine, jatrorrhizine, } \\
\text { palmatine }\end{array}$ & $\begin{array}{l}\text { Sichuan, } \\
\text { China }\end{array}$ & Dry bark & 3 \\
\hline$E Z h u$ & $\begin{array}{c}\text { Curcuma aeruginosa } \\
\text { Roxb. } \\
\text { [C.zedoarianonRosc.] }\end{array}$ & $\begin{array}{c}\text { Rhizome } \\
\text { curcumae }\end{array}$ & $\begin{array}{l}\text { Inhibit hepatoma cell } \\
\text { proliferation, induced } \\
\text { apoptosis of liver } \\
\text { cancer cells, anti-liver } \\
\text { fibrosis } \\
\end{array}$ & $\begin{array}{c}\text { Volatile oil (curzenone, } \\
\text { borneo1, pormacrone), } \\
\text { curcumene, cudione, turme }\end{array}$ & $\begin{array}{c}\text { Guangxi, } \\
\text { China }\end{array}$ & Tuber root & 6 \\
\hline Bie Jia & $\begin{array}{l}\text { Trionyx sinensis } \\
\text { (Wiegmann) }\end{array}$ & Turtle Shell & $\begin{array}{c}\text { Anti-liver } \\
\text { fibrosis, promote } \\
\text { immunity, anti- } \\
\text { hepatocyte injury }\end{array}$ & $\begin{array}{c}\text { Collagen, trionyx sinesis } \\
\text { polysaccharides, Amino } \\
\text { acid (aspartic acid, } \\
\text { hreonine, glutamic acid), } \\
\text { Calcium carbonate, calcium } \\
\text { phosphate }\end{array}$ & $\begin{array}{l}\text { Hubei, } \\
\text { China }\end{array}$ & Carapace & 3 \\
\hline $\begin{array}{c}\text { Jiao } \\
\text { Shan } \\
\text { Zha }\end{array}$ & $\begin{array}{c}\text { Crataegus } \\
\text { pinnatifida Bunge } \\
\text { var.major N.E.Br. }\end{array}$ & Hawthorn Fruit & $\begin{array}{c}\text { Lower } \\
\text { cholesterol, anti- } \\
\text { bacterial, anti- } \\
\text { hypertensive }\end{array}$ & $\begin{array}{c}\text { Epicatechin, quercetin, } \\
\text { hyperoside, chlorogenic } \\
\text { acid, anthocyanin, ursolic } \\
\text { acid }\end{array}$ & $\begin{array}{l}\text { Shandong, } \\
\text { China }\end{array}$ & Fruit & 15 \\
\hline $\begin{array}{c}\text { Bai } \\
\text { Shao }\end{array}$ & PaconialactifloraPall. & $\begin{array}{l}\text { Radix paeoniae } \\
\text { alba }\end{array}$ & $\begin{array}{c}\text { Anti-hepatocyte } \\
\text { injury, anti-liver } \\
\text { fibrosis, anti-fatty } \\
\text { liver }\end{array}$ & $\begin{array}{c}\text { Paeoniflorin, oxy- } \\
\text { paeoniflorin, } \\
\text { benzoylpaooniflorin, albi- } \\
\text { florin, paeoniflorigenone }\end{array}$ & $\begin{array}{c}\text { Anhui, } \\
\text { China }\end{array}$ & Rhizome & 12 \\
\hline $\begin{array}{l}\text { Ling } \\
\text { Xiao } \\
\text { Hua } \\
\end{array}$ & $\begin{array}{l}\text { Campsis grandiflora } \\
\text { (Thunb.)K.Schum. }\end{array}$ & $\begin{array}{l}\text { Trumpetcreeper } \\
\text { Flower }\end{array}$ & $\begin{array}{l}\text { Anti-oxidation, inhibit } \\
\text { thrombosis, anti- } \\
\text { inflammatory }\end{array}$ & Apigenin, $\beta$-sitos-terol & $\begin{array}{c}\text { Jiangsu, } \\
\text { China }\end{array}$ & Flower & 6 \\
\hline Bai Zhu & $\begin{array}{c}\text { Atractylodes } \\
\text { macrocephala Koidz. }\end{array}$ & $\begin{array}{l}\text { Largehead } \\
\text { Atractylodes } \\
\text { Rhizome }\end{array}$ & $\begin{array}{c}\text { Inhibit liver cancer } \\
\text { cell } \\
\text { metastasis, promote } \\
\text { cellular immune } \\
\text { function, inhibit the } \\
\text { activating of } \\
\text { metabolic enzymes }\end{array}$ & 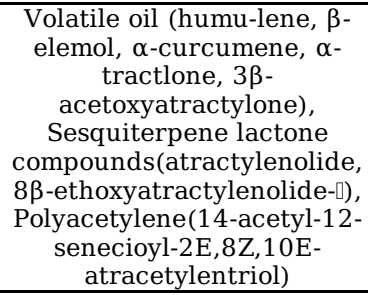 & $\begin{array}{c}\text { Zhejiang, } \\
\text { China }\end{array}$ & Tuber root & 9 \\
\hline Fu Ling & $\begin{array}{c}\text { Poria } \\
\text { cocos } ₫ \text { Schw. } \square \text { Wolf. }\end{array}$ & Tuckahoe & $\begin{array}{l}\text { Enhance cellular and } \\
\text { humoral immunity, } \\
\text { inhibit the DNA } \\
\text { synthesis of tumor } \\
\text { cell, inhibit } \\
\text { hepatocyte necrosis, } \\
\text { anti-tumor }\end{array}$ & $\begin{array}{c}\text { pachymic acid, tumulosic } \\
\text { acid, pachymic acid methyl } \\
\text { ester, pachy-man, } \\
\text { Pachymaran, }\end{array}$ & $\begin{array}{c}\text { Yunnan, } \\
\text { China }\end{array}$ & Dry sclerotia & 9 \\
\hline $\begin{array}{c}\text { Chai } \\
\mathrm{Hu}\end{array}$ & $\begin{array}{l}\text { Bupleurum chinense } \\
\text { DC. }\end{array}$ & $\begin{array}{l}\text { Red Thorowax } \\
\text { Root }\end{array}$ & $\begin{array}{c}\text { Anti-liver } \\
\text { fibrosis, inhibit acute } \\
\text { liver injury, inhibit } \\
\text { proliferation of liver } \\
\text { cancer cells, promote } \\
\text { apoptosis of liver } \\
\text { cancer cells, anti-liver } \\
\text { injury } \\
\end{array}$ & $\begin{array}{l}\text { Volatile oil (pentanoic acid, } \\
\text { hexanoic acid, heptanoic } \\
\text { acid, 2-heptenoic acid } \square\end{array}$ & $\begin{array}{l}\text { Hebei, } \\
\text { China }\end{array}$ & Rhizome & 6 \\
\hline $\begin{array}{l}\text { Bai Hua } \\
\text { She } \\
\text { She } \\
\text { Cao }\end{array}$ & $\begin{array}{l}\text { Hedyotis diffusa } \\
\text { Willd. }\end{array}$ & $\begin{array}{c}\text { Spreading } \\
\text { Hedyotis Herb }\end{array}$ & $\begin{array}{l}\text { Enhance hepatocyte } \\
\text { immunogenic to anti- } \\
\text { tumor, inhibit } \\
\text { proliferation of liver } \\
\text { cancer cells, promote } \\
\text { apoptosis of liver } \\
\text { cancer cells } \\
\end{array}$ & $\begin{array}{c}\text { Asperuloside } \square \\
\text { asperulosidic acid } \square \\
\text { deacetylasperulosidicacid } \square \\
\text { genipoSidic acid } \square \\
\text { scandoside }\end{array}$ & $\begin{array}{c}\text { Guangxi, } \\
\text { China }\end{array}$ & Whole plant & 12 \\
\hline
\end{tabular}




\section{Figures}

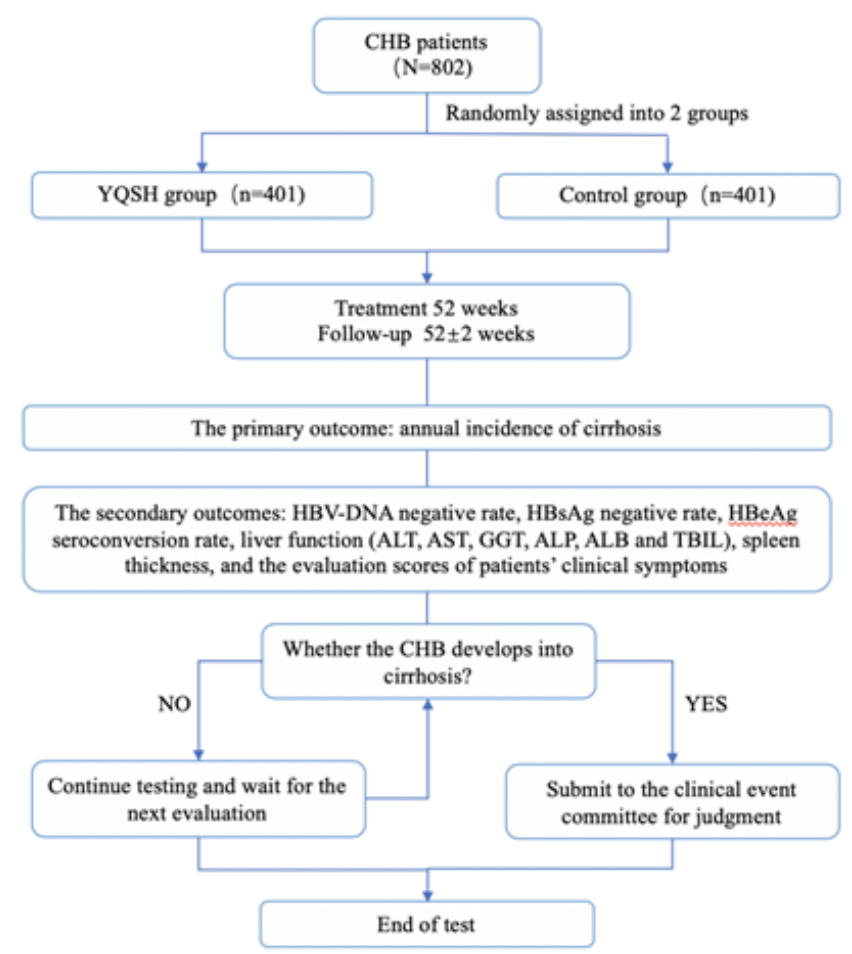

\section{Figure 1}

Flow chart of the randomized, placebo-controlled, double-blinded trial of YQSH for CHB. Abbreviations $₫ a)$ CHB, chronic hepatitis B. b) YQSH, YinQiSanHuang-antiviral decoction. c) ALT, alanine aminotransferase. d) AST, aspartate aminotransferase. e) GGT, gamma glutamyl transferase. f) ALP, alkaline phosphatase. g) ALB, serum albumin. h) TBIL, total bilirubin. 


\begin{tabular}{|c|c|c|c|c|c|c|}
\hline \multirow[b]{3}{*}{ TIMEPOINT $^{\star *}$} & \multicolumn{6}{|c|}{ STUDY PERIOD } \\
\hline & \multirow{2}{*}{$\begin{array}{c}\text { Enrolment } \\
-3 w k s-0 d \\
\end{array}$} & \multirow{2}{*}{$\begin{array}{c}\text { Allocation } \\
\text { 0d }\end{array}$} & \multicolumn{2}{|c|}{ Treatment } & \multicolumn{2}{|c|}{ Follow-up } \\
\hline & & & $26 w k s \pm 14 d$ & $52 w k s \pm 14 d$ & $26 w k s \pm 14 d$ & $52 w k s \pm 14 d$ \\
\hline \multicolumn{7}{|l|}{ ENROLMENT: } \\
\hline \multirow{2}{*}{$\begin{array}{l}\text { Eligibility screen } \\
\text { Informed consent }\end{array}$} & $\mathrm{X}$ & & & & & \\
\hline & $\mathrm{X}$ & & & & & \\
\hline Allocation & & $\mathrm{X}$ & & & & \\
\hline \multicolumn{7}{|l|}{ INTERVENTIONS: } \\
\hline \multicolumn{7}{|l|}{ Placebo group } \\
\hline \multicolumn{7}{|l|}{ YQSH group } \\
\hline \multicolumn{7}{|l|}{ ASSESSMENTS: } \\
\hline $\begin{array}{r}\text { Safety } \\
\text { outcomes }\end{array}$ & $\mathrm{x}$ & & $\mathrm{x}$ & $\mathrm{X}$ & $\mathrm{X}$ & $\mathrm{x}$ \\
\hline $\begin{array}{r}\text { Primary outcome: } \\
\text { annual incidence } \\
\text { of cirrhosis }\end{array}$ & & & $\mathrm{X}$ & $\mathrm{X}$ & $\mathrm{X}$ & $\mathrm{X}$ \\
\hline $\begin{array}{r}\text { Secondary } \\
\text { outcomes }\end{array}$ & & & $\mathrm{x}$ & $\mathrm{X}$ & $\mathrm{X}$ & $\mathrm{X}$ \\
\hline
\end{tabular}

\section{Figure 2}

The schedule of enrollment, interventions and assessments demonstrated in the Standard Protocol Items: Recommendations for Interventional Trials (SPIRIT) Figure

\section{Supplementary Files}

This is a list of supplementary files associated with this preprint. Click to download.

- SPIRITchecklist20191128.docx

- EthicalApprovalDocuments.pdf

- fundingdocumentation.docx 